\title{
O FADO DANÇADO DO BRASIL: TRÂNSITOS CULTURAIS
}

\author{
José Machado Pais \\ Universidade de Lisboa, Lisboa, Portugal
}

\section{Resumo:}

Entre uma multiplicidade de possíveis filiações musicais e coreográficas, o lundu afro-brasileiro alcançou uma justificada relevância na história do fado, recentemente aprovado como Património Imaterial da Humanidade da Unesco. Nessa matriz, o fado dançado tinha marcas de uma grande sensualidade e, assim, surgiu nas tabernas e prostíbulos da Lisboa boémia de meados do século XIX. Ao aburguesarse - e, sobretudo, com o advento da ditadura salazarista (1926) -, o fado lisboeta deixou de ser dançado, perdendo uma boa parte da sua expressividade corporal. Porém, na Baixada Fluminense, ainda sobrevive um fado que remonta aos tempos da escravatura, dançado com palmas, sapateado, pandeiros e violas. Recorrendo a fontes históricas e etnográficas, o presente contributo questiona as práticas corporais associadas ao fado por referência aos seus contextos ideológicos.

Palavras-chave: Tradição. Cultura. Etnicidade. Mudanças Sociais.

\section{Introdução}

s trajetórias do fado fluem por encruzilhadas de labirinto (CAS-
TORIADIS, 1978): caminhos e descaminhos que nos dão conta da sua variabilidade. No entanto, se nessas vias e transvias nos podemos achar como intérpretes da história do fado, também é possível que nelas nos possamos extraviar. Laplantine (2007, p. 27) indica dois principais modos de extravio: ou quando nos situamos deliberadamente "acima da realidade", ordenando-a hierarquicamente a partir de uma perspetiva a-histórica; ou quando nos situamos "por debaixo" dela, buscando seus fundamentos, origens ou primórdios, numa perspetiva histórico-evolucionista. Quer uma quer outra abordagem dificultam o entendimento dos processos de transmutação que caracterizam a realidade do fado. Num caso, o fado seria o que é independentemente do que foi; noutro caso seria um mero efeito de determinismos com ori- 
gens mais ou menos místicas ou líricas. O que se propõe é uma metodologia de registos históricos que nos permitam uma aproximação à história do fado a partir de práticas corporais associadas à sua dança.

Num primeiro momento, veremos que o fado que se descobre na Lisboa de meados do século XIX evidencia fortes influências afrobrasileiras. A sensualidade do lundu, notória nos primeiros registos sobre a dança do fado no Brasil, aparece também nos fados e fandangos que se ouvem e dançam nas tabernas e bordéis da Lisboa boémia. Porém, com o aburguesamento do fado - e, sobretudo, com o advento do salazarismo (1926) -, como é que a ideologia moralista do regime enfrentaria uma manifestação cultural de raízes essencialmente populares e bairristas e que, simultaneamente, se desenvolvia com plangências, lamentos e sensualidade em antros de prostituição, marginalidade e vadiagem? O que veremos é que os fadistas começam a ser perseguidos como um bando de marginais e só mais tarde o fado se reabilitará, apropriado pelo próprio regime ideológico que o escorraçou, como canção emblemática de uma identidade nacional.

Entretanto, no labirinto dos seus percursos, viemos a descobrir, em Quissamã (Brasil), um fado que remonta aos tempos da escravatura. Um fado dançado com palmas, sapateado, pandeiros e violas. É um achado intrigante pois várias fontes históricas sugerem que em Lisboa do século XIX, o fado antes de o ser (cantado, com acompanhamento à guitarra) já o era (dançado, em versão afandangada, com castanholas, sapateado, pandeiros e violas). Mas então por que razão o fado de Lisboa fugiu desse registo, deixando de ser dançado? Recorrendo a fontes históricas, mas também a uma etnografia do fado de Quissamã, o presente contributo questiona, em diferentes latitudes geográficas, as práticas corporais associadas ao fado, tendo em conta os respetivos contextos ideológicos da sua produção e recepção.

\section{A sensualidade corporal do fado de outrora}

Em Portugal, as origens do fado rodopiam, de forma mais ou menos mitificada, entre várias possíveis origens. Os influxos afro-brasileiros têm sido dos mais valorizados, nomeadamente através do lundu, também chamado de lundum (TINHORÃO, 1994; BRANCO, 1929 e FRYER, 2000). Um filão menos explorado é o da possível relação do fado com as modinhas (NERY, 2004, p. 30-35) que se impunham como canções de salão de autores eruditos mas que também ecoavam, 
em versão popular, como músicas de rua, frequentemente cantadas por cegos pedintes. Acompanhando a fuga apressada da família real para o Brasil, as modinhas confraternizaram com o lundu. Antes, contudo, nos tempos do rei D. Miguel, nas hortas dos arrabaldes de Lisboa, já as guitarradas acompanhavam as modinhas. Esses convívios da aristocracia, conhecidos por frescatas, acabariam por acolher estroinas e prostitutas. Emergia então o fado ligado à boémia, guitarreado e cantado nas tascas de Lisboa e nas esperas de touros (PAIS, 2008). De fato, o fado aparece como

uma síntese, estilizada por séculos de lenta evolução, de todas as influências que afetavam o povo de Lisboa [...]. No ritmo sincopado pode discernir-se a influência de danças exóticas de África ou do Brasil, populares em Lisboa desde que o batuque foi introduzido, no século XVI, nos dias do oitavo, da arrepia, do guinéu, do zabel macau, do charamba, do sarambeque, do canário e da fofa, até ao 'doce lundum chorado' de Tolentino. (GALLOP, 1960, p. 18).

Trazido para o Brasil por escravos bantos, majoritariamente provenientes de Angola, o lundu, dança cantada e, inicialmente, com acompanhamento a batuque, tornou-se muito popular mesmo antes da chegada da Corte portuguesa, em 1808. Os lundus tinham coreografias próximas às das umbigadas, nomeadamente no que respeita aos movimentos lascivos. Em Cartas chilenas, atribuída a Tomás António Gonzaga, faz-se referência a lundus dançados no palácio do governo de Vila Rica, na década de 1780, nos seguintes termos:

[...] Fingindo a moça que levanta a saia

E voando na ponta dos dedinhos

Prega no machacaz, de quem mais gosta,

A lasciva umbigada, abrindo os braços;

Então o machacaz, mexendo a bunda,

Pondo uma mão na testa, outra na ilharga,

Ou dando alguns estalos com os dedos,

Seguindo das violas o compasso

Lhe diz - 'eu pago, eu pago' - e de repente,

Sobre a torpe michela atira o salto.

(GONZAGA, 1942, p. 334). 
O relato é significativo por revelar umbigadas lascivas na dança do lundu, para além do provocante «levantar da saia» da moça que depois vamos descobrir ser uma meretriz (michela) a quem o meliante promete pagamento («eu pago, eu pago»), acabando, todavia, por lhe atirar o «salto». Por saltos ou saltos de prateleira eram também designados os sapatos usados pelos ciganos na dança flamenga e, mais tarde, pelos fadistas da Lisboa boémia do século XIX. (PAIS, 2008).

A sensualidade do lundu encontra-se em alguns dos primeiros registos que existem sobre o fado no Brasil. Com efeito, observações anotadas por um oficial alemão, de passagem pelo Brasil entre 1825 e 1826, avançavam: "A dança favorita dos pretos chama-se Fado. Consiste num movimento que faz ondular suavemente e tremer o corpo, e que exprime os sentimentos mais voluptuosos da pessoa de uma maneira tão natural como indecente" (SCHLICHTHORST, 1824, apud NERY, 2004, p. 20). Pela mesma época, também um versejador português, Felisberto Cordeiro, ido para o Brasil em 1811, publicara um livro, em 1827, onde referia que "em espaçoso terreiro" vira "bailar mui bem Mimoso Fado" (CORDEIRO, 1827, apud TINHORÃO, p. 807; PINTO, 1931, p. 18-19). Mas já antes, nos anos sessenta do século XVII, haveria fado bailado no Rio de Janeiro, segundo indicação de Frederico de Freitas (ENCICLOPÉDIA LB, 8, p. 259-266), valendose de Varnhagen, quando refere um "preto mestiço ter cantado modinhas e bailado o fado".

De um e outro lado do Atlântico, os portugueses afeiçoaram-se ao lundu. Em sua Viagem pitoresca através do Brasil, Rugendas (18021858), para quem o fandango não passava de uma "imitação aperfeiçoada" do lundu, dá-nos conta de como os portugueses se envolviam animadamente nessa dança, acompanhando-a a violão (RUGENDAS, 1941, p. 197). Paulatinamente, de "dança de pretos" o lundu transformou-se em dança de salão. Em inícios do século XIX, no Rio de Janeiro, era famoso o designado "Lundu Lá no Largo da Sé", contando com reconhecidos modinheiros, como Cândido Inácio Silva (ANDRADE, 1999). Também em Lisboa se dançava o lundum. Com efeito, já no reinado de D. Manuel I (1495-1521) se proibira "não só a exibição do lundum, como igualmente a do batuque e a da charamba, por serem danças indecorosas" (ENCICLOPÉDIA LB, p. 742-745). Aliás, surgem também sinalizações do lundum quer em Sá de Miranda (século XVI) - "Este era el tiempo y sazon/ El logar este era aqui/ Las palabras de londom" (MIRANDA, 1804, p. 192, apud. BRAGA, 
1885, I, p. 397) - quer em Nicolau Tolentino (século XVIII), quando alude ao "doce lundum chorado":

Em bandolim marchetado,

Os ligeiros dedos promptos

Louro peralta adamado,

Foi depois tocar por pontos

O doce Lundum chorado.

(BRAGA, 1885, p. 397).

Nas tascas de Lisboa e arrabaldes, o fandango cruzou-se com o lundu, tal como no Brasil, e ambos com o fado (LAPLANTINE, 2000, p. 25-35). Um viajante de passagem por Portugal no terceiro quartel do século XVIII (1772-3) referia: "Foi em Mafra que tive o prazer de ver dançar o Fandango. Foi numa tasca. Foi dançado pelo dono da tasca com sua mulher, e com o acompanhamento duma guitarra. $\mathrm{O}$ tocador dedilhava várias cordas juntamente, a três tempos, e batia com a mão o compasso no corpo do instrumento" (TWISS, 1776, apud BRANCO, 1879, p. 264). Depois de sublinhar que viu o fandango em dança de pares, continuou:

Os dançantes estão num movimento geral com o corpo, e todos os membros, algumas vezes até indecentemente: marcam o compasso com o pé e com castanholas. Havendo falta deste instrumento, marca-se a cadência com estalos de dedos. O homem tem o chapéu posto na cabeça, e dança com sua dama chegando-se e afastando-se, e fazendo numerosas reviravoltas e requebros. (TWISS, 1776, apud BRANCO, 1879, p. 266).

Em 1848 há também registo romanceado de um lundum dançado numa tasca da Madragoa, uma dessas "espeluncas que a título de uma licença para venderem vinho e aguardente", eram "o centro do mais torpe deboche" (CARVALHO, 1849, p. 3). Quais as personagens que lá encontramos? Num canto havia o taberneiro, trajado à moda dos marujos; um preto, grumete de um navio brasileiro que trocara a agitada água dos mares pela tranquila água ardente; uma rapariga de 16 ou 17 anos, de feições formosas e "estragos da bebedice" e dois soldados, evadidos dos quartéis, quase embriagados. Noutro canto encontrava-se um jovem boémio "de jaqueta, chapéu à Cristina, cintas de seda enro- 
lada à fadista, calça de cetim enlameada, fumando no seu charuto de cinco reis" e que frequentemente repetia: - Oh patrão! Dê-me outra Francisquinha» (Carvalho, 1849, p. 7) O preto aparece depois a "atirar-se" à rapariga, por entre requebros de lundum, acompanhado a cavaquinho, tocado por um dos soldados. Em inícios do século XIX, eram já conhecidas as casas de fado como antros de prostituição e pousos prediletos de fadistas. Um velho boémio que se retratava como "ratão já de cabelos brancos", frequentador de "casas de fado", desvairava-se com prostitutas "que ao som da Banza sebenta" cantavam "como pretas rebolando" (ANÓNIMO, 1838, p. 5).

\section{Do fado boémio ao fado reprimido}

Como vimos, é nas tascas e prostíbulos dos bairros mais populares da cidade de Lisboa que, ao longo do século XIX, se desenvolve o ambiente da fadistagem, integrando fadistas e amantes do fado: prostitutas, marialvas, toureiros, boleeiros, vagabundos, marinheiros, etc. A arte de manipulação das cordas de guitarra estendia-se à manipulação de golpes de navalha. A navalha era uma amante predileta do fadista. Quando faltava a navalha, os golpes eram a paulada ou a pontapé. As próprias fadistas, quase todas prostitutas, não deixavam de manejar a navalha com mestria. A "Barbuda", mãe da mítica Severa, era bem conhecida por ser uma mulher de "faca na liga, cabelinho na venta e língua de prata". A taberna impunha-se pelo vinho, petisqueiras, chinfrim. Porém, no espaço da boémia lisboeta havia uma convivência espontânea, não estratificada, entre os diferentes segmentos sociais que a compunham. Esta mestiçagem em convivência era bem evidente nas esperas de touros, onde o fado era dançado ao compasso de chulipas (ligeiro pontapé na bunda do par dançante), e onde as chazadas nas hortas, normalmente regadas a vinho, proporcionavam uma fusão de jalecas e cintas, com corpos à mistura. Nas esperas de touros e nas chazadas participavam prostitutas e fadistas famosas, como a Severa, a Joaquina dos Cordões (que de tantos que tinha lhe veio o nome), a Júlia Gorda, a Faneca, a Perinha de Cheiro (pela aguardente, certamente), a Conceição Capelista, etc. Estas "putas de lei", como eram conhecidas, iam indistintamente para a cama com marialvas ou marinheiros, fadistas ou boleeiros. A Severa caía indistintamente nos braços do Conde de Vimioso e nos do Chico do Alegrete, um marinheiro rufia.

Pensar a Prática, Goiânia, v. 15, n. 1, p. 1-271, jan./mar. 2012 
Já para finais do século XIX, acentua-se um movimento de aburguesamento do fado, mas os fadistas rufias e as guitarras pífias persistiam nas velhas tascas dos bairros mais populares de Lisboa. Os maiores esforços de domesticação do fado surgem com a ditadura salazarista. Logo em 1927, os moralistas do regime com poder legislativo determinam a obrigatoriedade de posse de carteira profissional para se atuar em público, ao mesmo tempo em que proíbem os fados noturnos - precisamente aqueles que se tocavam nos bordéis e tascas (PAIS, 1986). O argumento da proibição era a defesa dos "cidadãos pacíficos e laboriosos", supostamente "acordados a altas horas por vozes roucas e avinhadas" (PAIS, 1996). Com a profissionalização do fado, amordaçavam-se as vozes rufias do fado que o cantavam, reivindicando-se a figura do fadista "honesto" e "trabalhador": aquele que, em surdina, o ensaiava na fábrica, de preferência assobiado, ao "som do martelo" ou do "raspar da polaina". O fado sente-se então perseguido e, depois da meia-noite, no ambiente de tasca que o viu nascer, é tocado baixinho, de portas fechadas, clandestinamente. Alguns fadistas da "gema" haveriam de abraçar o profissionalismo, mas isso não os impedia de sussurrarem o que lhes ia na "alma" - um sentimento de perseguição: "Já não se ouvem lindos temas / Na rua do fado Menor / A guitarra traz algemas / O Fado foi p'ró major"' (alusão ao major Moura que, no período da ditadura militar, era o terror policial dos fadistas).

É nesta efervescência ideológica (PAIS, 1990) que o fado acaba por se subjugar ao regime, para poder sobreviver, e é então que se desenvolve e consolida o mito do fado como símbolo da identidade nacional lusa. De manifestação de "margem", o fado torna-se bandeira de um regime, de uma nação. Os próprios defensores do fado boémio recorrem a argumentos patrióticos para a defesa do "velho fado". Por exemplo, quando se discute o perigo de os vigores da raça se dissolverem no vinho, na imprensa afeita à causa do fado (principalmente na Guitarra de Portugal e na Canção do Sul) escarniava-se dos jovens pálidos e dengosos que se entregavam ao capilé, chocolate e copinhos de leite por, numa atitude antipatriótica, agravarem a crise vinícola ("bebam vinho, para dar de comer a um milhão de portugueses!"). Reclama-se então o verdadeiro fado - o fado nacional - em tempos de valorização de tudo o que era português: do vinho verde ao cozido à portuguesa, das províncias ultramarinas às touradas (também "à portuguesa"). A invenção do fado como "tradição nacional" foi produto de 
um longo processo. O fado "típico" constitui-se como um estilo evidentemente artificial mas, para ter eficácia simbólica, precisou de ser encarado como tradição.

No correr do tempo, contudo, o fado não deixou de, amarguradamente, cantar o seu próprio fado, reavivando memorialmente as suas origens, a sua sina, o seu destino. Este sentimento persistente de ligação ao passado (margem do tempo) haveria de dicotomizar o fado em dois géneros: castiço ou vadio e o profissional ou turístico, não sendo raro vermos este último a reivindicar as suas velhas ambiências de alfurjas e prostíbulos ("Velha tendinha / és o templo da Pinguinha / os dois bancos, da gimbrinha / da boémia e do pifão", Fado da Tendinha, cantado por Hermínia). Isto é, a reivindicação de um outro estilo de fado, do "fado de antigamente" (fado castiço) deu profundidade e respeitabilidade histórica ao mito do fado como tradição nacional.

\section{Quissamã: reminiscências do fado dançado}

E eis que me confrontei com um achado. Em Quissamã, na região Norte Fluminense, sobrevive um fado que remonta aos tempos dos engenhos de açúcar, "casas grandes" e senzalas. Há tempos que sabia da existência deste fado, sendo enorme a minha curiosidade por o conhecer. Em Julho de 2009 viajei para Quissamã para ver e ouvir ao vivo esse fado, entrevistar fadistas e realizar um documentário ${ }^{1}$. O meu interesse por esta relíquia cultural aumentara com a candidatura do fado a património imaterial da UNESCO, recém-aprovada. No âmbito dessa candidatura, num colóquio internacional sobre o fado ${ }^{2}$, explorei algumas influências que fizeram com que o fado, antes de o ser (apenas cantado, com acompanhamento à guitarra) já o fosse (em versão afandangada, dançado com castanholas, sapateado, pandeiros e violas). E, quando chego a Quissamã, o que vejo? Um fado dançado com sapateado e palmas.

1-Trailer disponível em: http://www.youtube.com/watch?v=sw6m1YPk6eQ Para a realização (2010) do documentário (O Fado é bom demais...) contei com o apoio amigo e dedicado do Prof. Paulo Carrano, da Universidade Federal Fluminense.

2-Congresso Internacional Fado: Percursos e Perspetivas, organizado pela Universidade Católica (CEPCEP), Universidade Nova de Lisboa (INET-MD) e Museu do Fado, Lisboa, Junho de 2008.

Pensar a Prática, Goiânia, v. 15, n. 1, p. 1-271, jan./mar. 2012 
Havendo fontes históricas que o localizam no último quartel do século XVIII, as origens do fado de Quissamã encontram-se envoltas em mistério. Há quem o considere originário das quadrilhas que acompanharam D. João VI na sua ida para o Brasil e que depois animaram as festas dos senhores coloniais, sendo posteriormente recriadas por escravos e serviçais; há também quem o assemelhe ao "vira português" e ainda quem o tome como derivação de um "fandango de negros". Porém, no mito popularmente mais enraizado reivindica-se que "o fado é de Deus!" Para alguns fadistas, Jesus mesmo chegou à região de pandeiro e viola debaixo do braço e por isso o fado é dançado em cruz. Violas e pandeiros acompanham este fado dançado e cantado por vezes, ao desafio. Embora com variações, a dança evolui em grupos de quatro pessoas (dois homens e duas mulheres) cujos pares se cruzam depois de um forte sapateado e batimento de palmas por parte dos homens (outrora usavam-se tamancos). Enquanto isso, as mulheres rodopiam ou balanceiam-se com leveza.

O fado de Quissamã parece inscrever-se no universo das chamadas danças batidas, como eram conhecidos alguns fandangos dançados no Brasil - fandangos batidos, por implicarem sapateados e que terão certamente relação com o fado batido, muito em voga nas suspeitas tascas de Lisboa de finais do século XIX. Assim acontecia com a famosa dança da Maria Cachucha, tão famosa que acabou por aportar ao Brasil, como nos refere Renato de Almeida em sua História da música brasileira. As cantigas versejavam vulgaridades: "Maria Cachucha / Com quem dormes tu? / Com um menininho / Chamado Angu!". Também em Memórias de um sargento de milícias na descrição da dança do fado lá encontramos a viola, os estalos de dedos, o sapateado, as viravoltas e os batimentos de palmas. O fado de Quissamã navega nesta confluência de circunavegações, de origens e destinos por determinar. E por isso é tão fascinante, por seu fascínio estar no seu mistério. Por exemplo, qual o significado dos movimentos em cruz por parte dos dançantes, com toadas de sapateado? Possivelmente, a coreografia deste fado é um reflexo de socializações e permutações entre a cultura colonialista e expressões culturais dos que à força se tornaram escravos. Não podemos esquecer que o fado de Quissamã sobrevive numa região de jongo. Aliás, alguns fadistas são também jonguistas. Dona Guilhermina, uma fadista descendente de escravos, residente na Fazenda da Machadinha, referiu-me: "Eu conheci o fado e conheci o jongo, o jongo é de um jeito o fado é de outro, só que o fado é de 
Deus o jongo não é. Porque que o fado é de Deus? O fado é de Deus porque ele é cruzado".

O depoimento de Dona Guilhermina, infelizmente já falecida, aponta para relações de oposição e associação entre o fado e o jongo. O jongo apareceu como uma de múltiplas expressões de uma polifonia cultural que se espalhou por Terras de Vera Cruz com crenças religiosas e práticas ritualísticas ligadas à Umbanda que, para os cristãos mais ortodoxos, desafiavam, pela mão de Satanás, os seguidores da fé de Cristo (ARAÚJO, 1994). O diabo teve uma forte presença nos horizontes imaginários dos povos cristãos que se lançaram na expansão colonizadora das Américas. A expansão ultramarina lusa sempre apareceu associada à propagação da fé cristã, como se fora uma vasta empresa exorcista contra demónios e forças satânicas (HOLANDA, 1977). A missão cruzadística de combate às heterodoxias pagãs estendia-se a todas as latitudes da vida pessoal e coletiva. Todos os atos da vida quotidiana poderiam ser pretexto para a reivindicação e afirmação da cruz para que o diabo dela fugisse. A cruz era também usada contra os malefícios e sortilégios de feitiços e macumbas. Não estranha que as práticas associadas à Umbanda fossem vistas, pela colonização portuguesa, como expressão maléfica do diabo (AZZI, 1978). O jongo, em particular, aparecia associado a pretos velhos, feiticeiros filiados em irmandades negras que estavam, supostamente, por detrás de atos de insubordinação por parte dos escravos. Por tal razão, o Tribunal do Santo Ofício perseguia calundus, candomblés e tudo o mais que pudesse perigar o domínio dos ditames da Igreja Apostólica Romana (PRIORE, 1994).

Na Baixada Fluminense do período colonial, sempre houve uma convivência de missas ladainhas e procissões com canjerês, feitiços e amuletos (LAMEGO FILHO, 1934, p. 28). Contudo, o catolicismo entrevia nas danças africanas obscuros sentimentos, perigosas emoções, secretas paixões que davam asilo à superstição. A disputa colocava frente a frente as artimanhas do diabo (supostamente protagonizadas pelo jongo) e os poderes de Deus (representados pela cruz do fado). A cruz era considerada o "Lenho Sagrado" (SOUZA, 1993, p. 30). Considerando que a Baixada Fluminense teve uma forte presença de jesuítas, não estranha que a cruz acabasse por imperar na dança do fado de Quissamã. Em Arizes, por exemplo, abundavam vários marcos jesuíticos delimitando as propriedades dos religiosos, nas margens do rio Paraíba. Esses marcos tinham um símbolo característi- 
co: uma cruz inscrita num círculo. Nos engenhos onde existia capela, os escravos eram obrigados a assistir ao terço e à celebração da missa. Eram também obrigados ao batismo, recebendo nomes cristãos. Ulisses, dançador e cantador de fado de Quissamã ganhou, por batismo, o nome de Espírito Santo. O uso dos tamancos, não apenas para sapateado mas também para batimento sonoro, em substituição das mãos, terá também razões ocultas. Será que o seu uso, na dança do fado de Quissamã, terá surgido como resposta ao preconceito contra os tambores do jongo? Não nos podemos esquecer que sempre a música foi usada para expressar identidades e construir barreiras simbólicas entre diferentes grupos sociais...

\section{Conclusão}

Quanto mais esgravatamos as origens do fado - ou dos fados, em suas versões plurais - mais adensamos o seu mistério. E isto por quê? Porque a história do fado também é feita de narrações e mitos que alimentam e dão forma à imagem de si que o fado nos dá: no modo como o pensamos, mas também no jeito como a sua história se conta na forma como se canta e dança. Neste pequeno contributo, tomado que foi um tempo de longa duração, constatou-se que no fado se cumpre um relativo assimilacionismo de culturas caldeadas, simultaneamente sincréticas e longínquas. Sincréticas uma vez que o fado resulta de entrecruzamentos etnoculturais diversos. Mas, ao mesmo tempo, culturas longínquas, cuja sobrevivência se encontra associada a modos de exploração colonial, de negros escravos trazidos de longe para viverem no inferno de uma existência penosa. Desse modo, não espanta que o fado evoluísse num leito ladeado por duas margens: o lundum e o fandango. Aliás, não por acaso, na viragem do século XVIII para o XIX, Andrew Grant, em sua History of Brazil, publicada em 1808, caracterizava a dança brasileira como resultante do cruzamento do fandango com danças africanas. Também Mário de Andrade se refere a um lundum brasileiro que, na sua coreografia, integra manifestações corporais de influências europeias, como o "erguer dos braços", o "estalar dos dedos", as "palmas" e o "sapateado". Aliás, nas antigas mourarias, berço do fado lisboeta, encontrávamos as malagueñas, em versões afandangadas. São essas marcas sincréticas, africanas e europeias, que encontramos no fado de Quissamã cujos fadistas reclamam que "o fado é de Deus", como se o mistério das suas origens nos desa- 
fiasse a descobrir, na dimensão mítica das mesmas, a realidade social que lhe subjaz e que insiste em se fazer pensar.

Entretanto, quando em Portugal dissecamos a passagem do fado boémio para o fado reprimido, surgiu-nos um outro enigma. Por que razão o fado de Lisboa se imobilizou numa voz que preferencialmente canta de olhos fechados? Por que razão é que o fado português aparece atualmente como simples expressão da voz que o canta? Por que deixou o fado de ser dançado (PAIS, 2003)? Nas suas Mitologias, LéviStrauss mostrou que alguns mitos da América do Sul se referem à relação da música com as máscaras rituais e a palavra: a música como palavra mascarada; a palavra instrumento de comunicação. $O$ fado privilegiou inicialmente os aspetos coreográficos, os ritos de máscara, a dança, o corpo. Isto aconteceu na matriz afro-brasileira do fado. A desmascaração ocorre num processo de mudança civilizacional que fez com que o fado se afastasse das suas raízes, da sua versão dançada, ficando apenas a voz, tudo o mais silenciado: silêncio que se vai cantar o fado, costuma ouvir-se em Lisboa, onde ele é cantado. À primeira vista poderíamos supor que a ditadura salazarista - com todos os seus códigos moralistas - teve um papel decisivo na repressão da expressividade corporal do fado, isto é, na sufocação da sua coreografia. É uma hipótese sustentável que, todavia, não elimina outras. Gilberto Freire apontava noutra direção, ao sugerir que, analisadas pelo prisma da sua relação com a sexualidade, as danças eróticas correspondem à carência, não ao excesso (FREIRE, 1995, p. 100). Nesse sentido, tais danças poderiam ser mais procuradas - embora clandestinamente - em períodos de maior repressão da sexualidade. Qualquer que seja o caso - e aqui convergiríamos para a conclusão final deste contributo - as práticas corporais ganham um estatuto de centralidade na discussão das transformações culturais.

\title{
Fado danced in Brazil: Cultural passer
}

\begin{abstract}
Among a multitude of possible affiliations to music and dance, african-Brazilian lundu reached a justified importance in the history of fado, recently approved as Intangible Heritage of Humanity by UNESCO. In this matrix, fate had danced marks a great sensuality and thus arose in taverns and brothels of bohemian Lisbon midnineteenth century. When aburguesar up - and especially with the advent of the Salazar dictatorship (1926) - fado from Lisbon no longer danced, losing much of its expressiveness body. However, in the Lowlands, a fate that still survives since the time of slavery, danced with palms, tap dancing, tambourines and guitars. Drawing
\end{abstract}


on ethnographic and historical sources, this contribution argues against corporal practices associated with fado by reference to their ideological contexts.

Keywords: Fado. Lundu. Bohemia. Cultural Passer. Bodily Practices.

\section{El fado bailado en Brasil: tránsitos culturales}

\section{Resumen}

Entre una multitud de posibles afiliaciones a la música y la danza afro-brasileña lundu alcanzado una importancia justificada en la historia del fado, aprobado recientemente como Patrimonio Inmaterial de la Humanidad por la UNESCO. En esta matriz, el destino había bailado marca una gran sensualidad y así surgió en las tabernas y burdeles de la bohemia de Lisboa a mediados del siglo XIX. Cuando aburguesar arriba - y sobre todo con el advenimiento de la dictadura de Salazar (1926) fado de Lisboa ya no se baila, perdiendo gran parte de su cuerpo, la expresividad. Sin embargo, en las tierras bajas, un destino que aún se conserva desde la época de la esclavitud, bailó con las palmas, baile tap, panderetas y guitarras. Basándose en las fuentes etnográficas e históricas, esta contribución se opone a las prácticas corporales asociados con el fado por referencia a sus contextos ideológicos.

Palabras clave: Fado. Lundu. Bohemia. Tránsitos Culturales. Prácticas Corporales.

\section{Referências}

ALMEIDA, R. História da música brasileira. Universidade do Texas, 1926.

ANDRADE, M. Cândido Inácio da Silva e o Lundu. Revista de Música Latinoamericana, vol. 20, $\mathrm{n}^{\mathrm{o}} 2$ (Outono-Inverno), 1999, p. 215233.

ANÓNIMO. Queixumes das pequenas. Lisboa: Typ. De Nery, $2^{\mathrm{a}}$ edição, 1838.

ARAÚJO, M. B. Magia, demónio e força mágica na tradição portuguesa: séculos XVII e XVIII. Lisboa: Edições Cosmos, 1994.

AZZI, R. A cristandade colonial. Um projeto autoritário. São Paulo: Paulinas, 1978.

BRAGA, T. O povo português nos seus costumes, crenças e tradições (2 volumes). Lisboa: Livraria Ferreira Editora, 1885.

BRANCO, L. F. A música em Portugal. Lisboa: Escola Tipográfica da Imprensa de Lisboa, 1929. 
CARVALHO, J. C. Eduardo ou Os mistérios do limoeiro ( $1^{\circ}$ tomo). Lisboa: Tipografia da Revolução de Setembro, 1849.

CORDEIRO, F. I. J. Obras poéticas de Falmeno. In: JANCSÓ, I.; KANTOR, I. (orgs.), Festa, cultura e sociabilidade na América portuguesa, vol. II. São Paulo: Edusp, 2001.

CASTORIADIS, C. Encruzilhadas do labirinto. Os domínios do homem. Rio de Janeiro: Paz e Terra, 1987.

ENCICLOPÉDIA LUSO-BRASILEIRA DE CULTURA. Lisboa: Editorial Verbo, $8^{\circ}$ Volume.

ENCICLOPÉDIA LUSO-BRASILEIRA DE CULTURA. Lisboa: Editorial Verbo, $12^{\circ}$ Volume.

FREIRE, G. Casa-Grande \& senzala. Rio de Janeiro: Record, 1955.

FREITAS, F. Fado. In: ENCICLOPÉDIA LUSO-BRASILEIRA DE CULTURA. Lisboa: Editorial Verbo, $8^{\circ}$ Volume.

FRYER, P. Rhythms of Resistance: African Musical Heritage in Brasil. Londres: Pluto Press, 2000.

GALLOP, R. Cantares do povo português. Lisboa: Instituto de Alta Cultura, 1969.

GONZAGA, T. A. Obras completas. São Paulo: Nacional, 1942.

HOLANDA, S. B. Visão do paraíso. São Paulo: C. Editora Nacional, 1977.

LAMEGO FILHO, A. A planície do solar e da senzala. Rio de Janeiro: Livraria Católica, 1934

LAPLANTINE, F. Do Rio de Janeiro a Lisboa, do fado dançado ao fado cantado. A questão das origens afro-brasileiras do fado. In: AMORIM, M. M.; ARAÚJO, N. (orgs.), Imaginário, cultura e mundo do trabalho: Perspectivas contemporâneas. São Paulo: Terceira Margem, 2000. 
LAPLANTINE, F.; NOUSS, A. Mestizajes. De Arcimboldo a Zombi. Buenos Aires: Fondo de Cultura Económica, 2007

MELLO E SOUZA, L. Inferno atlântico. Demonologia e colonização. Séculos XVI-XVII. São Paulo: Companhia das Letras, 1993.

NERY, R. V. Para uma história do fado. S.1.: Edição do Público, 2004.

PAIS, J. M. Austeridade e moralismo dos padrões estéticos. In: REIS, A. (dir.). Portugal contemporâneo (1926-1958), Volume 4. Lisbon: Publicações Alfa, 1990, p. 349-352.

Fado. In: ROSAS, F.; BRITO, J. M. B. (coord.), Dicionário de história do Estado Novo (Volume I). Lisboa: Círculo de Leitores, 1996, p. 340-342. 2003.

Vida cotidiana. Enigmas e revelações. São Paulo: Cortez,

A prostituição e a Lisboa boémia: do século XIX a inícios do século XX. Porto: Âmbar, 2008.

PINTO, M. S. O lundum avô do fado. Ilustração, nº 6, Novembro, 1931.

PRIORE, M. D. Religião e religiosidade no Brasil colonial. São Paulo: Ática, 1994.

RUGENDAS, J. M. Viagem pitoresca através do Brasil. São Paulo: Livraria Martins ( $3^{\mathrm{a}}$ edição), 1941.

SCHLICHTHORST, C. Rio de Janeiro wie es ist., Hannover, Im Verlage Hahn'schen Hofbuchhandlung. In: NERY, R. V. Para uma história do fado, Lisboa: Edição do Público, 2004.

TINHORÃO, J. R. Fado. Dança do Brasil, cantar de Lisboa. O fim de um mito. Lisboa: Caminho, 1994.

TWISS, R. Voyage en Portugal et en Espagne fait en 1772 e 1733, Berne, chez la Société Typographique. In: BRANCO, M. B. Portugal 
e os estrangeiros (tomo II). Lisboa: Livraria de A. M. Pereira-Editor, 1879

Recebido em: 23/10/2011

Revisado em: 15/11/2011

Aprovado em: 18/01/2012

Endereço para correspondência

machado.pais@ics.ul.pt

José Machado Pais

Universidade de Lisboa

Instituto de Ciências Sociais

Avenida Professor Aníbal de Bettencourt, 9

1600-189 Lisboa, Portugal 